\title{
The impact of shift work on the psychological and physical health of nurses in a general hospital: a comparison between rotating night shifts and day shifts
}

Paola Ferri'

Matteo Guadi'

Luigi Marcheselli'

Sara Balduzzi'

Daniela Magnani'

Rosaria Di Lorenzo

'Department of Diagnostic, Clinical and Public Health Medicine, University of Modena and Reggio Emilia, ${ }^{2}$ Department of Mental Health, AUSL di Modena, Service of Psychiatric Diagnosis and Treatment, Modena, Italy

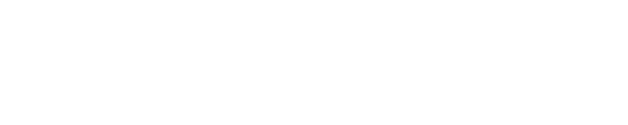

Background: Shift work is considered necessary to ensure continuity of care in hospitals and residential facilities. In particular, the night shift is one of the most frequent reasons for the disruption of circadian rhythms, causing significant alterations of sleep and biological functions that can affect physical and psychological well-being and negatively impact work performance. Objectives: The aim of this study was to highlight if shift work with nights, as compared with day work only, is associated with risk factors predisposing nurses to poorer health conditions and lower job satisfaction.

Methods: This cross-sectional study was conducted from June 1, 2015 to July 31, 2015 in 17 wards of a general hospital and a residential facility of a northern Italian city. This study involved 213 nurses working in rotating night shifts and 65 in day shifts. The instrument used for data collection was the "Standard Shift Work Index," validated in Italian. Data were statistically analyzed. Results: The response rate was $86 \%$. The nurses engaged in rotating night shifts were statistically significantly younger, more frequently single, and had Bachelors and Masters degrees in nursing. They reported the lowest mean score in the items of job satisfaction, quality and quantity of sleep, with more frequent chronic fatigue, psychological, and cardiovascular symptoms in comparison with the day shift workers, in a statistically significant way.

Conclusion: Our results suggest that nurses with rotating night schedule need special attention due to the higher risk for both job dissatisfaction and undesirable health effects.

Keywords: shift work, night work, health, sleep disorders, job satisfaction, nurses

\section{Introduction}

Nowadays, almost a fifth of the worldwide workforce is engaged in shift work, with 20\% of European and American workers engaged in night shifts. ${ }^{1,2}$ In the health care system, shift work is considered necessary and indispensable to ensure continuity of care in hospitals and residential facilities. Rotating and scheduling are the main characteristics of shift work and nurses are largely locked into schedules that provide 24-hour care and include night shift work. ${ }^{3}$ An author has noted that "shift workers are creators and victims at the same time" of this new work organization. ${ }^{4}$ Shift work, and night shift in particular, is one of the most frequent reasons for the disruption of circadian rhythms, causing significant alterations of sleep and biological functions, which, in turn, can affect the physical and psychological well-being and negatively condition work performance..$^{5-7}$ Many studies have analyzed the impact of shift work on the physical health of workers. In particular, some authors identified a maladaptation syndrome related to shift work, characterized
Correspondence: Paola Ferri Department of Diagnostic, Clinical and Public Health Medicine, University of Modena and Reggio Emilia, Street Del Pozzo no 7I, 4I I24, Modena, Italy Tel +390594223528

Fax +390594222520

Email paola.ferri@unimore.it 
by impaired sleeping/waking, gastrointestinal disorders, and an increased risk of cardiovascular diseases. ${ }^{8}$ Recently, a syndrome called "shift work disorder" has been identified by the presence of the following symptoms: alteration of circadian rhythm of sleep/wake, insomnia, excessive day sleepiness, and fatigue. ${ }^{9,10}$ Different percentages of shift work disorder have been reported in cross-sectional studies, ranging from $24.4 \%$ to $44.3 \%{ }^{2,11-13}$ Most studies highlighted that the overall quality of sleep among night shift nurses was significantly poorer than that of day and no night-rotating workers. ${ }^{5,14,15}$ Night shift work induces sleep deprivation which, in turn, alters the daily levels of alertness and job performance, favoring fatigue., ${ }^{216}$ This condition, often associated with shifts, ${ }^{17-19}$ is probably due to the desynchronization of circadian rhythm or reduced sleep, ${ }^{20,21}$ similar to jet lag syndrome. ${ }^{22}$ The sleep alterations related to shift work have been included among the Circadian Rhythm Sleep-Wake Disorders, irregular type, of Diagnostic and Statistical Manual of Mental Disorders, 5th Edition (DSM-5), ${ }^{23}$ which reports a high frequency of this disorder among the night shift worker population (5\%-10\% of the workforce). A Greek study confirms that sleep disturbance that occurs in shift work is strongly associated with chronic fatigue. ${ }^{24}$ The symptoms of fatigue, including "sleepiness and lack of energy," "impaired concentration," and "feelings of discomfort," were more severe in the nurses who worked night shifts than others who worked during the day. ${ }^{25}$ Most authors observed that the fatigue related to night shifts can increase the risk of human errors and injuries and can negatively affect the quality of patient care. ${ }^{26}$ Moreover, fatigue reduces performance and job satisfaction, favoring absence due to sickness, absenteeism, turnover, and job attrition and often induces use of psychotropic drugs. ${ }^{27-30}$ Fatigue remains the major source of nurses' errors in administering medication. ${ }^{31}$ In a study by Jamal and Baba, rotating shift nurses showed a lower degree of job satisfaction. ${ }^{32}$ In a Greek nursing sample, the levels of job satisfaction measured by the Index of Work Satisfaction appeared to relate to shift work. ${ }^{33}$ Decreased job satisfaction for nurses is strongly associated with increased job stress. ${ }^{34}$ Health professionals who worked night shifts showed more psychological and mental health problems than day workers: irritability, somatization, obsessive-compulsive disorder, interpersonal sensitivity, anxiety, altered mood, and paranoid disorders were significantly higher. These data indicate that shift work has a negative impact on psychological health and social life. ${ }^{35-37}$ Much research concerning the potential effects of shift work on cardiovascular system has been conducted over the last 2 decades without producing conclusive findings. $8,38-40$ In some studies, the relative risk of cardiovascular diseases in night shift workers was higher than the risk reported by day workers. ${ }^{41,42}$ In a study conducted among 75,000 US nurses, the authors highlighted that mortality induced by cardiovascular and other causes was significantly increased among female nurses engaged in rotating night shift (RNS) work for $\geq 5$ years compared to women who had never worked night shifts, suggesting a potentially detrimental effect of RNS work on health and longevity. ${ }^{43}$ These results were confirmed by the meta-analysis of Lin et $\mathrm{al}^{44}$ who observed a $2.7 \%$ increase in cardiovascular deaths in RNS workers. Many gastrointestinal symptoms and disorders associated with shift work have been reported in literature for $>2$ decades: dyspepsia, gastritis, colitis, peptic ulcer, indigestion, appetite disorders, irregular bowel movements, constipation, heartburn, pain, abdominal rumblings, flatulence, and gastro-duodenitis ${ }^{8,45-47}$ Several factors may be involved in the gastrointestinal symptoms reported among shift workers: alterations of the circadian rhythm of gastric functions (gastric secretion, enzyme activity, and intestinal motility) and types of foods consumed, medication, psychosocial stress, and for women, altered menstrual cycle. ${ }^{48}$ A recent study has shown that abnormal eating habits were positively associated with shift work in a group of nurses. ${ }^{49} \mathrm{~A}$ Danish study noted that, in a sample of 29,000 nurses, night and evening shift workers presented an increased risk for diabetes. ${ }^{50}$ Moreover, the number of night shifts worked in the previous year was significantly and positively associated with the variations in the body mass index of the workers. ${ }^{51} \mathrm{On}$ the contrary, another recent study did not observe a different frequency of diseases between the night and the day shift (DS) workers in a sample of 525 Polish nurses and midwives, ${ }^{52}$ probably due to the so-called "healthy worker effect," as underlined by the authors. Finally, in 2007, the International Agency for Research on Cancer of the World Health Organization affirmed that there is sufficient evidence to support that shift work with circadian rhythm disruption is a probable carcinogen. ${ }^{53}$ This observation has been confirmed by a recent meta-analysis, which highlighted that night shift work enhanced the risk of breast cancer morbidity by $8.9 \%{ }^{44}$

Epidemiological studies as reported above have shown detrimental effects of shift work on health, but the pathological mechanisms related to shift work have not been completely elucidated. Moreover, up to now, satisfactory solutions to minimize shift work impact on health conditions have not been implemented. ${ }^{54}$ Many sleep, distress, or fatigue disorders of health workers are still underestimated as are other diseases, which frequently occur among professionals. ${ }^{7}$

The aim of this study is to highlight if shift work with nights, as compared with day work only, is associated with 
risk factors predisposing nurses to poorer health conditions and lower job satisfaction.

\section{Methods}

\section{Design and setting}

This study was a cross-sectional analysis conducted from June 1, 2015 to July 31, 2015 in 17 wards of a general hospital (neurology-stroke unit, geriatrics, post-acute geriatric treatment, emergency medicine, metabolic medicine, cardiovascular medicine, orthopedics, rehabilitation medicine, neurosurgery, post-acute extensive phase rehabilitation, vascular surgery, general surgery, medicine gastroenterology, cardiology, neurological and post-surgery intensive care, emergency department, and digestive endoscopy clinic) and in home care services in a northern Italian city.

\section{Sample}

In order to determine the sample size for the two groups of nurses, a pilot study involving 25 DS nurses was conducted in April 2015. The results of this preliminary analysis highlighted an average score of 26.26 ( \pm 6.63 standard deviation [SD]) for fatigue, which was the principal outcome of this research. Therefore, assuming that among nurses who performed three RNSs the score of fatigue was increased 3 points, the sample size, with a significance value of 0.05 and a power of 0.80 , was 2:1 in favor of night shift nurses. Nevertheless, as a $65 \%$ response rate to questionnaire was provided, the correct ratio between daily and night shift nurses was $\sim 3: 1$ in a total sample of minimum 260 individuals. The nurses involved in the preliminary study were excluded from the sample of this study.

The nurses $(n=278)$ who agreed to complete the questionnaire during the study period were recruited for our convenience sample: 213 nurses regularly working in three RNSs and 65 in DSs.

In our hospital, DS nurses worked morning and afternoon shifts according to a weekly timetable scheduled from Monday to Friday, whereas RNS nurses worked according to a 6-day cycle timetable with backward rotation and "quick return" (first day afternoon; second morning, third night, fourth the end of the previous night shift; fifth and sixth rest). In Table 1 , information regarding the shift timetable is shown in detail.

\section{Instrument}

The instrument used for data collection was the "Standard Shift Work Index" (SSI), ${ }^{55}$ translated in Italian. ${ }^{4}$ Before the administration of SSI, we held a meeting with the professionals of each hospital unit in order to give information about this research, encouraging their participation.
Table I Shift details: comparison between RNS and DS nurses

\begin{tabular}{|c|c|c|}
\hline $\begin{array}{l}\text { Shift scheduling } \\
\text { information }\end{array}$ & $\begin{array}{l}\text { RNS nurses } \\
(n=179)\end{array}$ & $\begin{array}{l}\text { DS nurses } \\
(n=53)\end{array}$ \\
\hline \multicolumn{3}{|c|}{ Morning: work shift start time, n (\%) } \\
\hline $6.00 \mathrm{am}$ & $2(1)$ & $0(0)$ \\
\hline $7.00 \mathrm{am}$ & I77 (99) & $30(57)$ \\
\hline $7.30 \mathrm{am}$ & $0(0)$ & $4(7)$ \\
\hline $8.00 \mathrm{am}$ & $0(0)$ & $15(28)$ \\
\hline $8.30 \mathrm{am}$ & $0(0)$ & $3(6)$ \\
\hline \multicolumn{3}{|c|}{ Morning: work shift finish time, $\mathrm{n}(\%)$} \\
\hline $12.00 \mathrm{pm}$ & $0(0)$ & $I(2)$ \\
\hline $1.00 \mathrm{pm}$ & $129(72)$ & $24(45)$ \\
\hline $1.30 \mathrm{pm}$ & $49(27)$ & $5(10)$ \\
\hline $2.00 \mathrm{pm}$ & $I(I)$ & $8(15)$ \\
\hline 3.00 pm & $0(0)$ & $15(28)$ \\
\hline \multicolumn{3}{|c|}{ Afternoon: work shift start time, $\mathbf{n}(\%)$} \\
\hline $1 \mathrm{I} .30 \mathrm{am}$ & $0(0)$ & $\mathrm{I}(2)$ \\
\hline $12.00 \mathrm{pm}$ & $0(0)$ & $6(11)$ \\
\hline $1.00 \mathrm{pm}$ & $129(72)$ & $4 \mathrm{I}(77)$ \\
\hline $1.30 \mathrm{pm}$ & $49(27)$ & $0(0)$ \\
\hline $2.00 \mathrm{pm}$ & I (I) & $0(0)$ \\
\hline \multicolumn{3}{|c|}{ Afternoon: work shift finish time, $\mathbf{n}(\%)$} \\
\hline $7.00 \mathrm{pm}$ & $0(0)$ & $35(66)$ \\
\hline $8.00 \mathrm{pm}$ & $179(100)$ & $13(24)$ \\
\hline \multicolumn{3}{|c|}{ Night: work shift start time, $n$ (\%) } \\
\hline $8.00 \mathrm{pm}$ & $179(100)$ & $0(0)$ \\
\hline \multicolumn{3}{|c|}{ Night: work shift finish time, $n$ (\%) } \\
\hline $6.00 \mathrm{am}$ & $2(1)$ & $0(0)$ \\
\hline $7.00 \mathrm{am}$ & $177(99)$ & $0(0)$ \\
\hline
\end{tabular}

Abbreviations: DS, day shift; RNS, rotating night shift.

The SSI is a self-report questionnaire with good psychometric properties that has been used to compare groups of shift workers working on different types of shift systems for assessing the impact of work on the health and well-being of individuals. This scale can be used as a whole battery, or in part, as all its measures are independent of each other, producing individual scores. ${ }^{55,56}$

We chose the following subsections of SSI, in accordance with the aims of this study:

1. "Work situation" consists of three questions investigating work seniority, experience, and time spent at work weekly.

2. "General job satisfaction" consists of five items which "measure the degree to which the employee is satisfied and happy with the job" with a 7-point score ranging from "disagree strongly" (score 1) to "agree strongly" (score 7).

3. "Information on shifts" consists of five questions concerning time spent on shifts, start and end of shifts, advantages or disadvantages of shifts, advance shift scheduling time, and less acceptable shift among morning, afternoon, and night. 
4. "Personal habits" consists of only two questions regarding daily personal habits (smoking and coffee consumption).

5. "Sleep" includes many questions aimed at investigating "sleep habits." We chose only four questions among all the sleep items, as shown in Table 5, which are evaluated by a Likert scale ranging from 1 (almost never) to 5 (almost always), "a score, of 5 being associated with high sleep disturbance."

6. "Chronic fatigue," indicated as "general tiredness and lack of energy," is composed of 10 items: "five questions are positively oriented to index general feelings of vigor and energy, the opposite of fatigue (the items are reverse recoded)" whereas the other five items investigate "general feelings of tiredness and lack of energy." The score is based on a 1-5-point Likert scale ("higher score is an indication of more fatigue").

7. "Physical health conditions" contains two subscales evaluating cardiovascular and gastrointestinal disorders: the first eight questions aimed at highlighting digestive conditions, and the second eight questions investigated cardiovascular conditions, with a Likert scale ranging from 1 to 4 - "A higher score on each scale is associated with poorer physical health."

8. "General health questionnaire," the 12 -item version we chose, is a self-administered test for detecting minor psychiatric disorders, with a multiple-response scale or "Likert scale" - "A higher score would indicate poorer psychological health."

9. "Injuries" is composed of two items for investigating the number of injuries at work reported in the last 3 years and the shift in which they occurred.

10. "Demographic and professional information" includes five items concerning age, sex, marital status, professional qualifications, and employment contract and hours worked per week. Cronbach's alpha for "job satisfaction," "poor sleep," "chronic fatigue," "physical health conditions," and "general health questionnaire" was $0.79,0.81,0.85,0.65$, and 0.82 , respectively.

\section{Statistical analysis}

After collecting the completed questionnaires, the variables were reported in EXCEL database. For continuous variables, numerical categories were chosen in a number sufficiently representative but not excessive and successively statistically analyzed with STATA program.

Categorical variables were reported as absolute and percentage frequencies. For continuous variables, mean and $\mathrm{SD}$ were calculated. We compared the scale score of each item between night and DS workers by using the Fisher's exact and chi-square test for categorical data and two-sided unequal unpaired $t$-test (adopting Satterthwaite degrees of freedom) for continuous data.

The association between the binary variable shift work and selected characteristics was analyzed by means of logistic regression and expressed as odds ratio (OR) with confidence interval at $95 \%(95 \% \mathrm{CI})$. The OR measures the strength of association between the characteristics of the cohort and DS worker. Positive OR means that the odds for the DS worker were greater when exposed to an increased value of covariates analyzed. Data were analyzed by using the statistical software Stata version 12 (2011).

\section{Ethical considerations}

This study was performed in accordance with the Declaration of Helsinki and was authorized by both the Medical Director and Director of Nursing of the General Hospital (NOCSAE) of Modena. The present study was approved by the Institutional Review Board of Local Nurses Association. All nurses provided written informed consent. The anonymity and confidentiality of participants were assured and their decision to participate voluntarily in this study was respected.

\section{Results}

The response rate was $86 \%$ (239/278). Seven of 239 questionnaires were excluded because they were incomplete. Results were extrapolated from 232 questionnaires. Demographic and professional data of our sample are shown in Table 2. RNS workers were statistically significantly younger than DS workers (38 \pm 7 vs $45 \pm 6$ SD years old on average; unpaired $t$-test; $P<0.001$ ). In both groups, $>70 \%$ of nurses were female. In all, $31 \%$ of RNS workers was single, compared with $9 \%$ of DS workers, in whom married status prevailed (64\%) in a statistically significant way (chi-square test; $P=0.002$ ). RNS workers more frequently had a degree in nursing, compared with DS nurses ( $83 \%$ vs $75 \%$, chi-square test, $P=0.003$ ), but they less frequently had an employment contract of indefinite duration in comparison to other group ( $86 \%$ vs $96 \%$, chi-square test, $P=0.033$ ). The professional experience, evaluated as years of work, statistically significantly differed between the two groups of nurses: 14.1 years on average in RNS nurses compared to 22.5 in DS nurses (unpaired $t$-test, $P<0.001)$, whereas the mean hours spent at work by the two groups did not show any statistically significant difference. Regarding job satisfaction, the rotating shift professionals reported the lowest mean score (23.1 $\pm 5.7 \mathrm{SD})$, whereas daily shift workers reported the highest mean score (26.4 $\pm 4.2 \mathrm{SD})$, with a statistically significant difference (unpaired $t$-test, $P<0.001$ ) (Table 3). Among all shifts, the afternoon shift 
Table 2 Sample characteristics: comparison between RNS and DS nurses

\begin{tabular}{|c|c|c|c|}
\hline Variables & $\begin{array}{l}\text { RNS nurses } \\
(n=179)\end{array}$ & $\begin{array}{l}\text { DS nurses } \\
(n=53)\end{array}$ & $P$-value \\
\hline \multicolumn{4}{|l|}{$\overline{\text { Age }}$} \\
\hline (years), $\mathrm{m} \pm \mathrm{SD}$ & $38 \pm 7$ & $45 \pm 6$ & $<0.001$ \\
\hline \multicolumn{4}{|l|}{ Sex, n (\%) } \\
\hline Male & $51(28)$ & II (2I) & 0.293 \\
\hline Female & $127(7 \mid)$ & $42(79)$ & \\
\hline Missing data & $I(I)$ & $0(0)$ & \\
\hline \multicolumn{4}{|l|}{ Marital status, $\mathbf{n}(\%)$} \\
\hline Single & $56(31)$ & $5(9)$ & 0.002 \\
\hline Married & $77(43)$ & $34(64)$ & \\
\hline Cohabiting & $37(21)$ & $9(17)$ & \\
\hline Divorced & $8(4)$ & $5(9)$ & \\
\hline Missing data & $I(I)$ & $0(0)$ & \\
\hline \multicolumn{4}{|l|}{ Education, n (\%) } \\
\hline Registered nurse & II (6) & $4(8)$ & \\
\hline Bachelor in nursing sciences & $149(83)$ & $40(75)$ & 0.003 \\
\hline Master in nursing sciences & $18(10)$ & $8(15)$ & \\
\hline Missing data & I (I) & I (2) & \\
\hline \multicolumn{4}{|c|}{ Employment contract, $n$ (\%) } \\
\hline Temporary & $26(14)$ & $2(4)$ & 0.033 \\
\hline Permanent & $153(86)$ & $51(96)$ & \\
\hline \multicolumn{4}{|l|}{ Work schedule, n (\%) } \\
\hline Full time & $165(92)$ & $49(92)$ & 1.000 \\
\hline Part time & $14(8)$ & $4(8)$ & \\
\hline \multicolumn{4}{|l|}{ Seniority } \\
\hline (years), $\mathrm{m} \pm \mathrm{SD}$ & $14.1 \pm 7.4$ & $22.5 \pm 7.5$ & $<0.001$ \\
\hline \multicolumn{4}{|l|}{ Hours worked per week } \\
\hline $\mathrm{m} \pm \mathrm{SD}$ & $35.3 \pm 2.5$ & $35.3 \pm 3.0$ & 0.926 \\
\hline \multicolumn{4}{|c|}{$\begin{array}{l}\text { Time worked in the present } \\
\text { shift system }\end{array}$} \\
\hline (years), $\mathrm{m} \pm \mathrm{SD}$ & $11.4 \pm 7.0$ & $10.0 \pm 7.0$ & 0.229 \\
\hline
\end{tabular}

Note: The values in bold are statistically significant.

Abbreviations: DS, day shift; $\mathrm{m}$, mean; RNS, rotating night shift; SD, standard deviation.

was the least appreciated, according to both groups. No statistically significant difference between the two groups was highlighted in the answers to the question whether the advantages associated with shift work outweighed the disadvantages. Concerning information on shifts, $73.1 \%$ of daily workers versus only $22.2 \%$ of RNS nurses reported that their shift timetable was scheduled months in advance (chi-square $=46.53, P=0.000)$. The personal habits (smoking cigarettes and caffeine assumption) of both groups did not statistically significantly differ.

Concerning chronic fatigue, as shown in Table 4, some items, but not the total scale, reported statistically significant higher scores in the group of rotating shift workers compared to other nurses (unpaired $t$-test): "I usually feel pretty apathetic" $(P=0.007)$, "I often feel exhausted" $(P<0.001)$, and "I feel exhausted most of the time" ( $P=0.026)$. The two groups presented a statistically significant difference in sleep disorders (Table 5). RNS nurses reported lower scores in sleep quality and quantity compared to DS nurses; in particular, they claimed to suffer from sleepiness during morning shifts (unpaired $t$-test, $P<0.001)$. The average score of digestive symptoms reported was $15.2( \pm 5.2 \mathrm{SD})$ in RNS workers and $14.2( \pm 4.3)$ among DS workers, without any statistically significant difference. Cardiovascular symptoms statistically significantly differed only for two items concerning "chest pains" $(1.4 \pm 0.6$ vs $1.2 \pm 0.4, P=0.036)$ and "chest tightness" $(1.3 \pm 0.6$ vs $1.1 \pm 0.4$, $P=0.036$ ), symptoms more prevalent among RNS workers. In all, $69.3 \%$ of RNS and $69.8 \%$ of DS workers did not report any workplace accident in the previous 3 years; most accidents reported by both groups occurred in morning shifts ( $62.5 \%$ and $36.4 \%$ among daily and rotating shift workers, respectively). At the psychiatric symptom subsection, RNS workers reported higher mean scores compared to the other group $(13.4 \pm 4.9 \mathrm{vs}$ 11.5 \pm 4 .2, unpaired $t$-test, $P=0.011$ ).

We highlighted statistically significant associations between work shifts and some characteristics of sample by means of multivariate multiple logistic regression: positive correlation between daytime work and quantity $(\mathrm{OR}=1.28$, 95\% CI: 1.01-1.62, $P=0.039)$ and quality $(\mathrm{OR}=1.41,95 \%$ CI: $1.09-1.83, P=0.009)$ of sleep, and negative correlation between daytime and feeling of tiredness ( $\mathrm{OR}=0.45,95 \%$ CI: $0.34-0.60, P<0.001)$.

\section{Discussion}

In our study, the response rate was relatively high in comparison with other studies, ${ }^{3,24,57}$ indirectly suggesting the potential impact of this issue on professional well-being. The

Table 3 Job satisfaction: comparison between RNS and DS nurses

\begin{tabular}{|c|c|c|c|}
\hline Answers to SSI "job satisfaction" items & RNS nurses $(n=179) m \pm$ SD & DS nurses $(n=53) m \pm S D$ & $P$-value \\
\hline Generally speaking, I am very satisfied with my nursing & $4.9 \pm 1.7$ & $5.7 \pm 1.1$ & 0.001 \\
\hline I frequently think of quitting this job & $2.7 \pm 1.9$ & $2.1 \pm 1.7$ & 0.057 \\
\hline I am generally satisfied with the kinds of activities I do in this job & $5.1 \pm 1.6$ & $5.8 \pm 0.9$ & 0.002 \\
\hline Most people in this job are very satisfied with it & $3.7 \pm 1.5$ & $4.1 \pm 1.7$ & 0.064 \\
\hline People in this job often think of quitting & $4.0 \pm 1.8$ & $3.1 \pm 1.8$ & 0.003 \\
\hline General job satisfaction & $23.1 \pm 5.7$ & $26.4 \pm 4.2$ & $<0.001$ \\
\hline
\end{tabular}

Note: The values in bold are statistically significant.

Abbreviations: DS, day shift; m, mean; RNS, rotating night shift; SD, standard deviation; SSI, Standard Shift Work Index. 
Table 4 Fatigue: comparison between RNS and DS nurses

\begin{tabular}{llll}
\hline Answers to SSI "fatigue" items & RNS nurses $(\mathbf{n = 1 7 9 )} \mathbf{~ m} \pm \mathbf{S D}$ & DS nurses $(\mathbf{n}=\mathbf{5 3}) \mathbf{~ m} \pm \mathbf{S D}$ & $\mathbf{P}$-value \\
\hline I generally feel I have plenty of energy & $2.9 \pm 0.8$ & $3.0 \pm 0.7$ & 0.285 \\
I usually feel drained & $2.0 \pm 0.9$ & $2.3 \pm$ I & 0.116 \\
I generally feel quite active & $3.1 \pm 0.8$ & $3.2 \pm 0.6$ & 0.583 \\
I feel tired most of the time & $2.5 \pm 0.9$ & $2.4 \pm 0.9$ & 0.289 \\
I generally feel full of vigor & $2.8 \pm 0.9$ & $2.7 \pm 0.8$ & 0.415 \\
I usually feel rather lethargic & $1.9 \pm 0.9$ & $1.5 \pm 0.6$ & $\mathbf{0 . 0 0 7}$ \\
I generally feel alert & $3.3 \pm 0.7$ & $3.2 \pm 0.7$ & 0.237 \\
I often feel exhausted & $2.4 \pm 0.9$ & $1.8 \pm 0.7$ & $<\mathbf{0 . 0 0 1}$ \\
I usually feel lively & $3.1 \pm 0.9$ & $3.1 \pm 0.7$ & 0.84 I \\
I feel weary much of the time & $2.3 \pm 0.9$ & $2.0 \pm 0.8$ & $\mathbf{0 . 0 2 6}$ \\
General feelings of fatigue & $26.3 \pm 6.3$ & $24.5 \pm 4.8$ & 0.060 \\
\hline
\end{tabular}

Note: The values in bold are statistically significant.

Abbreviations: DS, day shift; m, mean; RNS, rotating night shift; SD, standard deviation; SSI, Standard Shift Work Index.

Table 5 Sleep and tiredness: comparison between RNS and DS nurses

\begin{tabular}{|c|c|c|c|}
\hline Questions & $\begin{array}{l}\text { RNS nurses } \\
(n=179) m \pm S D\end{array}$ & $\begin{array}{l}\text { DS nurses } \\
(n=53) m \pm S D\end{array}$ & P-value \\
\hline \multicolumn{4}{|c|}{ How do you feel about the amount of sleep you normally get? } \\
\hline Morning shifts & $2.7 \pm 1$ & $3.3 \pm 0.9$ & $<0.001$ \\
\hline Afternoon shifts & $3.7 \pm 0.8$ & $3.8 \pm 0.6$ & 0.388 \\
\hline Night shifts & $2.4 \pm 1.2$ & - & - \\
\hline Days off & $3.6 \pm 1$ & $4 \pm 0.7$ & 0.054 \\
\hline \multicolumn{4}{|c|}{ How well do you normally sleep? } \\
\hline Morning shifts & $2.4 \pm 1$ & $3.4 \pm 0.8$ & $<0.001$ \\
\hline Afternoon shifts & $3.5 \pm 0.8$ & $3.8 \pm 0.8$ & 0.023 \\
\hline Night shifts & $2.5 \pm 1.2$ & - & - \\
\hline Days off & $3.8 \pm 0.9$ & $4 \pm 0.8$ & 0.218 \\
\hline \multicolumn{4}{|c|}{ How rested do you normally feel after sleep? } \\
\hline Morning shifts & $2.4 \pm 0.9$ & $3.3 \pm 0.8$ & $<0.001$ \\
\hline Afternoon shifts & $3.4 \pm 0.8$ & $3.8 \pm 0.8$ & 0.006 \\
\hline Night shifts & $2.4 \pm 1.2$ & - & - \\
\hline Days off & $3.7 \pm 0.9$ & $4 \pm 0.7$ & 0.052 \\
\hline \multicolumn{4}{|c|}{ Do you ever feel tired on what type of shift? } \\
\hline Morning shifts & $3.5 \pm 0.9$ & $3.4 \pm 0.6$ & 0.479 \\
\hline Afternoon shifts & $2.9 \pm 1$ & $2.9 \pm 0.8$ & 0.892 \\
\hline Night shifts & $3.8 \pm 1.1$ & - & - \\
\hline Days off & $2.5 \pm 1.1$ & $2.6 \pm 0.9$ & 0.632 \\
\hline \multicolumn{4}{|l|}{ Total score } \\
\hline Morning shifts & $11.3 \pm 2.1$ & $13.9 \pm 2.9$ & $<0.001$ \\
\hline Afternoon shifts & $9.4 \pm 2.1$ & $10.2 \pm 2.6$ & 0.058 \\
\hline Night shifts & $14.4 \pm 3.8$ & - & - \\
\hline Days off & $8.5 \pm 2.4$ & $9.4 \pm 3.1$ & 0.099 \\
\hline
\end{tabular}

Note: The values in bold are statistically significant.

Abbreviations: DS, day shift; m, mean; RNS, rotating night shift; SD, standard deviation.

demographic and professional characteristics of the two nurse groups significantly differed and reflected a particular work organization, which allocates nurses who are younger, single, less experienced and in good health to RNSs. ${ }^{52,57}$ In accordance with other authors, ${ }^{57}$ this unequal distribution between workers on RNS and DS could represent a natural selection of professionals based on their health and familial conditions or a sort of apprenticeship for younger workers, quite common in health care settings worldwide. The higher percentage of nurses with degrees in the RNS group was probably related to both their younger age and university nursing courses only recently available. Nevertheless, both RNS and DS nurses in our sample were employed for the same number of hours per week.

The comparison between the two groups highlighted that RNS nurses reported lower job satisfaction. In this regard, the literature data are conflicting as many authors have agreed on this point, ${ }^{32,33}$ but others have demonstrated that nurses' job satisfaction is independent of the modality of shift schedule. ${ }^{45,57} \mathrm{In}$ our sample, the RNS workers were informed of their shift schedules with less advance notice than DS nurses and this condition could have been a reason for dissatisfaction due to the difficulty in scheduling of both family duties and recreational activities. Moreover, in our research, reduced job satisfaction was associated with more frequent physical and psychological symptoms related to stress, suggesting a clear correlation between these two conditions, as indicated by other authors. ${ }^{34}$ The literature agrees in indicating that RNS work imposes circadian strain and leads to a greater number of physical and psychological symptoms with a higher risk for several chronic diseases than other shift schedules. ${ }^{5,43}$ The RNS nurses in our sample presented chronic fatigue, sleep alterations, cardiovascular, and minor psychiatric symptoms more frequently, although they were younger and with less family responsibilities than others. Our study highlighted that DS nurses presented a lower risk for developing insomnia whereas RNS nurses more frequently suffered from sleep disorders, which influenced their subsequent work performance. These results, in line with other studies, ${ }^{15,58}$ suggest that RNS work represents a stress factor, which can lead to chronic discomfort and mild somatic alterations, predisposing to the development of psychological and physical diseases.

We have to emphasize that the counterclockwise (afternoon/morning/night) and rapidly consecutive rotation 
implemented in our hospital did not favor rest and sleep between one shift and another due to both the rapid sequentiality and backward rotation of shift. In fact, the literature indicates that different clockwise rotations (morning/afternoon/night) could be more protective, as well as a no rapid sequential rotation as nurses require at least 4 days to adjust their circadian rhythms of cortisol secretions after a night shift. $^{22,59}$

RNS workers reported lower scores in sleep quality and quantity when they had to work morning shifts compared to DS nurses, suggesting that morning shifts should not start too early in order to permit adequate sleep and regeneration of energy. Our research suggests that night shift work, like jet lag, can frequently induce sleep disorder which, still underestimated, can represent a risk factor for poor mental and physical health as well as for accidents. ${ }^{7-23}$

\section{Limitations}

The main limits of this study consist of both its small sample, composed of two groups, RNS and DS, and the lack of a comparison with other hospitals and/or residential facilities. Moreover, its cross-sectional design does not permit us to completely evaluate the causal relationship between the workshift modality and the selected variables. Prospective research in larger samples collected in many health care environments could help us to investigate this topic in greater depth.

\section{Conclusion}

Our study is one of the few available on the work schedule organization of an Italian general hospital. It has contributed to highlight that RNS work can be a stress factor with an impact on worker's health and well-being, in particular on job satisfaction, quality and quantity of sleep, and psychological and cardiovascular conditions, frequently inducing chronic fatigue. Our results suggest that workers with rotating night schedule load need special attention and frequent health checks due to the higher risk for both job dissatisfaction and undesirable health effects. Nurse patient care requires a high level of responsibilities and careful attention. Consequently, working conditions should be optimized in order to provide an appropriate quality of care over a 24-hour period. In accordance with the World Health Organization definition of shift work as a risk condition for many health disorders, we suggest that implementing ergonomic criteria aimed at reducing the adverse effects of shift schedules can permit a better organization of health care. In fact, we can infer that if a shift work pattern is more respectful of the health and well-being of workers, it could improve the life quality of both workers and patients. The implications of stress work schedules could be relevant to the emotional welfare of health workers and their capacity to maintain compassion and empathy for the people in their care. ${ }^{60}$ This study, in accordance with most studies which highlighted a significant positive association between quick returns ( $<11$ hours off work between two work shifts) and insomnia, sleepiness, fatigue and other shift work disorders, ${ }^{13,61}$ contributes to indicate that a regulation of at least 11 hours off work between two work shifts, as applied in many European countries, could ensure more shift worker well-being. Moreover, we can underline that a shift schedule prepared sufficiently in advance could be more protective for private life, reducing causes of psychological stress and social maladjustment.

Our findings are relevant not only for individual nurses but also for education, service provision, and research. More studies are necessary to better analyze the burden of shift work on the health and well-being of workers and patients.

\section{Disclosure}

The authors report no conflicts of interest in this work.

\section{References}

1. Parent-Thirion A, Vermeylen G, van Houten G, et al. Fifth European working conditions survey. European Foundation for the improvement of living and working conditions. Available from: http:/www.eurofound.europa.eu/sites/default/files/ef_publication/field_ef_document/ ef1 182en.pdf. Accessed May 28, 2016.

2. Boivin DB, Boudreau P. Impacts of shift work on sleep and circadian rhythms. Pathol Biol (Paris). 2014;62(5):292-301.

3. Korompeli A, Muurlink O, Tzavara C, Velonakis E, Lemonidou C, Sourtzi P. Influence of shiftwork on Greek nursing personnel. Saf Health Work. 2014;5(2):73-79.

4. Costa G. Lavoro a turni e notturno. Organizzazione degli orari di lavoro e riflessi sulla salute [Shift and night work. Organization of working schedule and impacts on health]. Firenze: SEE; 2003. Italian.

5. Burch JB, Yost MG, Johnson W, Allen E. Melatonin, sleep, and shift work adaptation. J Occup Environ Med. 2005;47(9):893-901.

6. Costa G. Shift work and health: current problems and preventive actions Saf Health Work. 2010;1(2):112-123.

7. Costa G, Accattoli MP, Garbarino S, Magnavita N, Roscelli F. Sleep disorders and work: guidelines for health surveillance, risk management and prevention. Med Lav. 2013;104(4):251-266.

8. Matheson A, O'Brien L, Reid JA. The impact of shiftwork on health: a literature review. J Clin Nurs. 2014;23(23-24):3309-3320.

9. Black JE, Hull SG, Tiller J, Yang R, Harsh JR. The long-term tolerability and efficacy of armodafinil in patients with excessive sleepiness associated with treated obstructive sleep apnea, shift work disorder, or narcolepsy: an open-label extension study. J Clin Sleep Med. 2010;6(5):458-466.

10. Schwartz JR, Khan A, McCall WV, Weintraub J, Tiller J. Tolerability and efficacy of armodafinil in naïve patients with excessive sleepiness associated with obstructive sleep apnea, shift work disorder, or narcolepsy: a 12-month, open-label, flexible-dose study with an extension period. J Clin Sleep Med. 2010;6(5):450-457.

11. Drake CL, Roehrs T, Richardson G, Walsh JK, Roth T. Shift work sleep disorder: prevalence and consequences beyond that of symptomatic day workers. Sleep. 2004;27(8):1453-1462. 
12. Asaoka S, Aritake S, Komada Y, et al. Factors associated with shift work disorder in nurses working with rapid-rotation schedules in Japan: the nurses' sleep health project. Chronobiol Int. 2013;30(4):628-636.

13. Flo E, Pallesen S, Moen BE, Waage S, Bjorvatn B. Short rest periods between work shifts predict sleep and health problems in nurses at 1-year follow-up. Occup Environ Med. 2014;71(8):555-561.

14. Garde AH, Hansen AM, Hansen J. Sleep length and quality, sleepiness and urinary melatonin among healthy Danish nurses with shift work during work and leisure time. Int Arch Occup Environ Health. 2009;82(10):1219-1228.

15. Waage S, Pallesen S, Moen BE, Magerøy N, Flo E, Di Milia L, Bjorvatn B. Predictors of shift work disorder among nurses: a longitudinal study. Sleep Med. 2014;15(12):1449-1455.

16. Akerstedt T, Wright KP Jr. Sleep loss and fatigue in shift work and shift work disorder. Sleep Med Clin. 2009;4(2):257-271.

17. Josten EJ, Ng-A-Tham JE, Thierry H. The effects of extended workdays on fatigue, health, performance and satisfaction in nursing. JAdv Nurs. 2003;44(6):643-652.

18. McGettrick KS, O’Neill MA. Critical care nurses-perceptions of 12-h shifts. Nurs Crit Care. 2006;11(4):188-197.

19. Samaha E, Lal S, Samaha N, Wyndham J. Psychological, lifestyle and coping contributors to chronic fatigue in shift-worker nurses. $J A d v$ Nurs. 2007;59(3):221-232.

20. Edéll-Gustafsson UM, Kritz EI, Bogren IK. Self-reported sleep quality, strain and health in relation to perceived working conditions in females. Scand J Caring Sci. 2002;16(2):179-187.

21. Ruggiero JS. Correlates of fatigue in critical care nurses. Res Nurs Health. 2003;26(6):434-444.

22. Costa G. Summary preventive and corrective measures for shift workers. G Ital Med Lav Ergon. 2012;34(Suppl 3):S326-S328.

23. American Psychiatric Association. DSM-5 Manuale diagnostico e statistico dei disturbi mentali [Diagnostic and Statistical Manual of Mental Disorders, 5th Edition]. Milano: Raffaello Cortina Editore; 2014.

24. Korompeli A, Chara T, Chrysoula L, Sourtzi P. Sleep disturbance in nursing personnel working shifts. Nurs Forum. 2013;48(1):45-53.

25. Winwood PC, Winefield AH, Lushington K. Work-related fatigue and recovery: the contribution of age, domestic responsibilities and shiftwork. J Adv Nurs. 2006;56(4):438-449.

26. Muecke S. Effects of rotating night shifts: literature review. J Adv Nurs. 2005;50(4):433-439.

27. Nakata A, Haratani T, Takahashi M, et al. Association of sickness absence with poor sleep and depressive symptoms in shift workers. Chronobiol Int. 2004;21(6):899-912.

28. d'Errico A, Costa G. Socio-demographic and work-related risk factors for medium- and long-term sickness absence among Italian workers. Eur J Public Health. 2012;22(5):683-688.

29. Lu H, Barriball KL, Zhang X, While AE. Job satisfaction among hospital nurses revisited: a systematic review. Int J Nurs Stud. 2012;49(8): 1017-1038.

30. Stimpfel AW, Brewer CS, Kovner CT. Scheduling and shift work characteristics associated with risk for occupational injury in newly licensed registered nurses: An observational study. Int J Nurs Stud. 2015;52(11):1686-1693.

31. Vallières A, Azaiez A, Moreau V, LeBlanc M, Morin CM. Insomnia in shift work. Sleep Med. 2014;15(12):1440-1448.

32. Jamal M, Baba VV. Shiftwork and department-type related to job stress, work attitudes and behavioral intentions: a study of nurses. J Organ Behav. 1992;13(5):449-464.

33. Gouzou M, Karanikola M, Lemonidou C, Papathanassoglou E2, Giannakopoulou M. Measuring professional satisfaction and nursing workload among nursing staff at a Greek Coronary Care Unit. Rev Esc Enferm USP. 2015;49:15-21.

34. McVicar A. Scoping the common antecedents of job stress and job satisfaction for nurses (2000-2013) using the job demands-resources model of stress. J Nurs Manag. 2016;24(2):E112-E136.

35. Shields M. Shift work and health. Health Rep. 2002;13(4):11-33.
36. Selvi Y, Gulec M, Agargun MY, Besiroglu L. Mood changes after sleep deprivation in morningness-eveningness chronotypes in healthy individuals. J Sleep Res. 2007;16(3):241-244.

37. Bjorvatn B, Dale S, Hogstad-Erikstein R, Fiske E, Pallesen S, Waage S. Self-reported sleep and health among Norwegian hospital nurses in intensive care units. Nurs Crit Care. 2012;17(4):180-188.

38. Hublin C, Partinen M, Koskenvuo K, Silventoinen K, Koskenvuo M, Kaprio J. Shift-work and cardiovascular disease: a population-based 22-year follow-up study. Eur J Epidemiol. 2010;25(5):315-323.

39. Puttonen S, Härmä M, Hublin C. Shift work and cardiovascular disease pathways from circadian stress to morbidity. Scand J Work Environ Health. 2010;36(2):96-108.

40. Bøggild H. Settling the question - the next review on shift work and heart disease in 2019. Scand J Work Environ Health. 2009;35(3): 157-161.

41. Ha M, Park J. Shiftwork and metabolic risk factors of cardiovascular disease. J Occup Health. 2005;47(2):89-95.

42. Frost P, Kolstad HA, Bonde JP. Shift work and the risk of ischemic heart disease - a systematic review of the epidemiologic evidence. Scand J Work Environ Health. 2009;35(3):163-179.

43. Gu F, Han J, Laden F, et al. Total and cause-specific mortality of U.S. nurses working rotating night shifts. Am J Prev Med. 2015;48(3): 241-252.

44. Lin X, Chen W, Wei F, Ying M, Wei W, Xie X. Night-shift work increases morbidity of breast cancer and all-cause mortality: a metaanalysis of 16 prospective cohort studies. Sleep Med. 2015;16(11): 1381-1387.

45. Sveinsdóttir H. Self-assessed quality of sleep, occupational health, working environment, illness experience and job satisfaction of female nurses working different combination of shifts. Scand J Caring Sci. 2006;20(2):229-237.

46. Burch JB, Tom J, Zhai Y, Criswell L, Leo E, Ogoussan K. Shiftwork impacts and adaptation among health care workers. Occup Med (Lond). 2009;59(3):159-166.

47. Knutsson A, Bøggild H. Gastrointestinal disorders among shift workers. Scand J Work Environ Health. 2010;36(2):85-95.

48. Simmons L, Heitkemper M, Shaver J. Gastrointestinal function during the menstrual cycle. Health Care Women Int. 1988;9(3):201-209.

49. Wong H, Wong MC, Wong SY, Lee A. The association between shift duty and abnormal eating behavior among nurses working in a major hospital: a cross-sectional study. Int J Nurs Stud. 2010;47(8): 1021-1027.

50. Hansen AB, Stayner L, Hansen J, Andersen ZJ. Night shift work and incidence of diabetes in the Danish Nurse Cohort. Occup Environ Med. 2016;73(4):262-268.

51. Buchvold HV, Pallesen S, Øyane NM, Bjorvatn B. Associations between night work and BMI, alcohol, smoking, caffeine and exercise-a crosssectional study. BMC Public Health. 2015;15:1112.

52. Burdelak W, Bukowska A, Krysicka J, Pepłońska B. Night work and health status of nurses and midwives. Cross-sectional study. Med Pr. 2012;63(5):517-529.

53. Straif K, Baan R, Grosse Y, et al; WHO International Agency for Research on Cancer Monograph Working Group. Carcinogenicity of shift-work, painting, and fire-fighting. Lancet Oncol. 2007;8(12): 1065-1066.

54. Kantermann T, Juda M, Vetter C, Roenneberg T. Shift-work research: Where do we stand, where should we go? Sleep Biol Rhythms. 2010;8(2): 95-105.

55. Barton J, Spelten E, Totterdell P, et al. The Standard Shiftwork Index: a battery of questionnaires for assessing shiftwork-related problems. Work Stress. 1995;9:4-30.

56. Tucker P, Knowles SR. Review of studies that have used the standard shiftwork index: evidence for the underlying model of shiftwork and health. Appl Ergon. 2008;39(5):550-564.

57. Buja A, Zampieron A, Mastrangelo G, Petean M, Vinelli A, Cerne D, Baldo V. Strain and health implications of nurses' shift work. Int J Occup Med Environ Health. 2013;26(4):511-521. 
58. Øyane NM1, Pallesen S, Moen BE, Akerstedt T, Bjorvatn B. Associations between night work and anxiety, depression, insomnia, sleepiness and fatigue in a sample of Norwegian nurses. PLoS One. 2013;8(8):e70228.

59. Niu SF, Chung MH, Chu H, et al. Differences in cortisol profiles and circadian adjustment time between nurses working night shifts and regular day shifts: A prospective longitudinal study. Int J Nurs Stud. 2015; 52(7):1193-1201.
60. Ferri P, Guerra E, Marcheselli L, Cunico L, Di Lorenzo R. Empathy and burnout: an analytic cross-sectional study among nurses and nursing students. Acta Biomed. 2015;86(Suppl 2):104-115.

61. Eldevik MF, Flo E, Moen BE, Pallesen S, Bjorvatn B. Insomnia, excessive sleepiness, excessive fatigue, anxiety, depression and shift work disorder in nurses having less than 11 hours in-between shifts. PLoS One. 2013;8(8):e70882.
Risk Management and Healthcare Policy

\section{Publish your work in this journal}

Risk Management and Healthcare Policy is an international, peer-reviewed open access journal focusing on all aspects of public health, policy, and preventative measures to promote good health and improve morbidity and mortality in the population. The journal welcomes submitted papers covering original research, basic science, clinical and epidemiological studies, reviews and evaluations, guidelines, expert opinion and commentary, case reports and extended reports. The manuscript management system is completely online and includes a very quick and fair peerreview system, which is all easy to use. Visit http://www.dovepress.com/ testimonials.php to read real quotes from published authors. 